\title{
Catalytic degradation of waste plastic into fuel range hydrocarbons
}

\author{
Tiwari D.C. ${ }^{* 1}$, Ejaz Ahmad ${ }^{2}$, Kumar Singh K.K. ${ }^{2}$ \\ ${ }^{1 *}$ Institute of Engineering, Jiwaji University, Gwalior, Madhya Pradesh, India, Email: dctiwari2001@yahoo.com \\ ${ }^{2}$ Department of chemical Engineering, Institute of Engineering, Jiwaji University, Gwalior, MP, India, Email: ejaz.alchemy@gmail.com
}

\begin{abstract}
This process involves catalytic degradation of waste plastic into fuel range hydrocarbon i.e. petrol, diesel and kerosene etc. A catalytic cracking process in which waste plastic were melted and cracked in the absence of oxygen and at very high temperature, the resulting gases were cooled by condensation and resulting crude oil was recovered. From this crude oil various products petrol, diesel and kerosene etc. can be obtained by distillation. This process mainly consists of four units (1) reacting vessel or reaction chamber (2) condensation unit (3) receiving unit (4) distillation unit. More specifically the degradation of waste plastic except polyvinyl chloride (PVC) and polyethylene terephthalate (PET) over two commercial grade cracking catalysts, containing $20 \%$ and $40 \%$ ultra stable $Y$ zeolite, respectively, was studied in a semi-batch reactor. Also the effect of polymer catalyst ratio was studied on the formation of liquid hydrocarbons. The best results were obtained when polymer catalyst ratio was 4:1 and after this ratio the liquid yield decreases. Furthermore alternate method for disposal of waste plastic is also studied. And the results of this process are found to be better than other alternate methods which are used for the disposal of waste plastic.
\end{abstract}

Keywords- Polymer degradation, Catalytic cracking, zeolite, Waste Plastic Disposal

\section{Introduction}

The huge amount of plastic waste that resulted from the dramatic increase in polymer production gives rise to serious environmental concerns, as plastic does not degrade and remains in the municipal refuse tips for decade [1]. According to a nation wide survey conducted in the year 2003, more than 10,000 MT of plastic waste is generated daily in our country, and only $40 \mathrm{wt} \%$ of the same is recycled, balance $60 \mathrm{wt} \%$ is not possible to dispose off [2]. Plastic waste being more voluminous than organic waste takes up a lot of landfill space that is becoming a scare and expensive. And India has been a favored dumping ground for plastic waste mostly from industrialized countries like Canada, Denmark, Germany, U.K, the Netherlands, Japan, France and the United States of America. According to the govt. of India import data more than 59,000 tons and 61,000 tons of plastic waste have found its way into India in the year 1999 and 2000 respectively [3-4]. Plastic being nonbiodegradable get accumulated in the environment. If this problem is not addressed properly, it will lead to mountains of waste plastic [5]. Incineration, blast furnace, gasification are not much appreciated solution to the problem, as toxic gases are produced and their cost of production is quite high. The only sustainable solution is degradation of polymer into various smaller molecular weight fragments. Catalytic degradation of plastic waste offers considerable benefits as compared to thermal degradation and other methods used. Catalytic degradation occurs at considerably low temperature and forms hydrocarbons in the range of motor range fuel. In such degradation process, the most valuable fuel is obviously liquid fuel. Although gaseous products are useful too, as their burning can contribute to the energy demand of an endothermic polymer cracking process, excess gas production is not desirable. For such catalytic process mainly zeolite-based catalysts [6, 9-16] have been used by various authors and other alumina silicate such as silica alumina [6-9], zsm5 and MCM-type mesoporous materials [17] were used. In order to further improve the yield to liquid fuel in the plastic catalytic cracking, we recently introduced two commercial grade cracking catalysts, containing $20 \%$ and $40 \%$ ultra stable Y-zeolite, respectively. This study has shown the suitability of commercial cracking catalyst for such polymer degradation process. Furthermore $4: 1$ polymer catalyst ratio produces more hydrocarbons in liquid form. The test of commercial cracking catalysts is important as one of the options of commercializing this polymer degradation method is to co-feed polymer waste to existing refinery crackers [11, 14-16]. This paper reports on the results of our study of polymer degradation over commercial cracking catalysts. More specifically it's report about the technical feasibility of the commercial level production as well as the cost of plant and its effect on Indian economy.

\section{Experimental}

The model polymer feed was linear low density polyethylene (LLDPE) in scrap form with an average particle size in micrometer with a density of $.928 \mathrm{gm} / \mathrm{cm} 3$ and average molecular mass of $117 \mathrm{gm} / \mathrm{mole}$. The catalyst samples used were two commercial cracking catalyst1 and cracking catalyst2 containing $20 \%$ and $40 \%$ US-Y zeolite respectively with average particle size in micrometers. A thermocouple was used to measure the temperature in the range of 250-800 $\mathrm{K}$ and a pressure gauge was also attached to measure the pressure of the reactor.

\section{Experimental equipment and procedure}

The experimental apparatus for catalytic degradation of LLDPE and catalytic mixture 
consist of a semi-batch reactor made of borosilicate glass in which the reaction takes place; heated by a heating mental connected to a temperature controller. Prior to the reaction vacuum was created in the reactor to ensure that no oxygen is left there. Polymer mixed with catalyst was charged into the reactor at the beginning and the reactor was heated up. The polymer catalysts ratio was also varied to know its effect on liquid yield. The ratio is shown in the table I. The overall mass of polymer and catalyst was kept between $2.5 \mathrm{~g}$ to $3.5 \mathrm{~g}$. A constant set point for the controller was used throughout the $25 \mathrm{~min}$. of experiment, which resulted in the following temperature profile in given in fig. I in first $10 \mathrm{~min}$; a linear temperature increase was observed and then increased with slow rate for remaining 15 minutes. Liquid products were collected through the condenser in a collecting vessel kept in an ice bath. And then it was further sent to the department for GC equipped with flame ionization detector (FID). Four samples were collected during experiment and analyzed.

\section{Experimental calculation}

The conversions to volatile products were calculated as the fraction of initial mass of polymer reacted to form the volatile products. The yield of liquid product was calculated as the mass of liquid collected divided by the mass of the initial amount of polymer and represents the fraction of original polymer converted to liquid products. The selectivity to liquid products was calculated as the mass of liquid collected divided by the mass of reacted polymer. The coke yield was calculated by dividing the mass of nonvolatile polymer on the catalyst by original mass of polymer. The non-volatile polymer represents the coke formed on the catalyst. That can be seen visually at the end of the experiment. The coke concentration calculated by dividing the mass of coke by the mass of dried catalyst. The boiling point distribution of each liquid fraction was used to represent the liquid product distribution. A calibrated mixture containing normal alkanes, pentane to iso-octane (C5 -C20) was prepared and used to assign each retention time observed from chromatograph to boiling point. And hence finally we got the liquid fuel.

\section{Results and discussion}

The overall conversion, liquid yield and coke concentration obtained by cracking catalysts 1 and 2 are summarized in table II. Cracking catalyst 1 could fully degrade the polymer samples in all cases, even at low values of overall content of active zeolite. No polymer remnants were observed and coke formed on catalyst was the only form of the polymer not converted to volatile products. In terms of overall liquid yield, a maximum was observed around a ratio $4: 1$. In the same case of $4: 1$, the liquid yield was very close to $90 \%$, which is an exceptionally high value observed by us. The low coke yields reflect upon the high conversion values reached. However, coke concentrations, the ratio of formed coke to catalyst mass, were higher, as higher polymers to catalyst ratio were applied. High conversion values around $78 \%$ was obtained with cracking catalyst 2 at all different polymer to catalyst ratios studied. Once again, all conversion values were above $90 \%$. The liquid yields were not so high when compared to cracking catalyst 1 , but ratio $4: 1$ produced the highest value $(89 \%)$. Obviously, we can say that the liquid yield is dependent on the specific ratio of polymer to catalyst ratio. The liquid versus time graph is presented in fig. II for different polymer to catalyst ratios for commercial cracking catalyst 1 fort clearer interpretation of the results. It clearly indicate that ratio of polymer to catalyst $4: 1$ produces higher liquid yield (89\%) as compared to the rest, as well as higher liquid yield during the complete experimental. For catalyst 2 a decrease in liquid yield is observed with the catalyst content for all reaction times. The fig. II and fig. III suggests that the there exist a critical ratio of polymer to catalyst for maximum liquid yield.

\section{Product distribution}

From the experimental work with the analyses of liquid samples at different reaction times, the tendency has been confirmed that the liquid fractions formed at the later reaction times have a higher average boiling point .Obviously earlier samples formed at lower temperature are expected to contain a higher proportion of lower boiling points. Reactions at lower temperature on the other side are expected to lead into scission of smaller chain fragments, while the larger fragments that demand higher activation energies are broken away at higher temp. Furthermore, solid - phase cross - linking reactions change the nature of polymer reactant, making it more difficult to degrade. A shift is observe towards less volatile hydrocarbons from the first collected liquid sample to later samples, see from fig. IV for the case of cracking catalyst 1 at polymer to catalyst ratio $4: 1$. However for the same catalyst at 6:1 ratio, the results are different (fig. V). Clearly the first collected sample contains higher fraction of component with the boiling point lower than this of normal octane and correspondingly a higher fraction of heavy components than the second collected liquid sample. While at other polymer to catalyst ratios, i.e. all the polymers mass seems to undergo cracking reactions, at lower US-Y content obviously not all the polymer mass participates in degradation reactions possibly due to not being in contact with the catalyst. While the second liquid fraction is usually formed from the conversion of further reactions of already partially degraded polymer, it 
seems that the volatile components of the second collected sample at the system are formed from conversion of un-degraded polymer. Comparing the boiling point distribution of liquid fractions formed over-cracking catalyst 1 at 2:1 polymer to catalyst ratio and 1:1 ratio, fig. $\mathrm{VI}$, it is obvious that the lower concentration of polymer in second case cause a shift towards more volatile components. Due to the lower component of the first system of the liquid formed contained a lower amount of light hydrocarbons \& the higher amount of heavy hydrocarbons than the liquid formed in second case. A better inspection of the same composition for cracking catalyst 2 reveals a slightly different picture (fig. VII). A simple grouping of the liquid products into light \& heavy doesn't describe the full picture. Although the liquid fraction of the 1:1 system contains again more light components and more heavy components, but considerably less middle boiling point component than the 2:1 system does. It seems that in the $1: 1$ case the low boiling components are formed from further cracking of middle point rather than the decomposition of heavy one. These initial results indicate that heavy component break down into middle volatile components, which undergo further cracking into light hydrocarbons. The results reported are from preliminary studies. Furthermore detailed studies are needed in order for the exact nature of secondary cracking reactions to be revealed.

\section{Conclusion}

A clear trend of liquid hydrocarbon formation was observed with the catalyst content during the catalytic degradations of polyethylene over the commercial cracking catalysts. An initial sharp increase in the liquid yield at low US-Y content is followed by a gradual decline at higher values this result in a maximum of liquid yield at ratio around 4:1 compared with a pure US-Y systems. Further more it is very clear from the above experiment that waste plastic can be converted into liquid fuel that can directly used as fuel but it will be better to use the as LDO and HSD for furnace heating etc. the process is very cheap as the catalyst can be recovered and used again and again. Conversion of waste plastic into fuel will reduce dependence on fossil fuels as well as the one of the most critical problem can be solved. The process is $100 \%$ eco-friendly as nothing is left in the environment and getting rid of plastic waste. Sulfur content in the fuel generated is less than $0.002 \%$.

\section{Acknowledgement}

The authors would like to thank Miss Shraddha Chadar from Department of Chemical engineering, Institute of Engineering (Jiwaji University, Gwalior) India for her kind help in making layout and design of the several apparatus used. The authors would also like to acknowledge Mr. MD. Kausar Raza from Department of Chemistry, Jamia Millia Islamia University, New Delhi for his valuable help related to reaction engineering.

\section{References}

[1] 'The Hindu' dated 25/09/03 and central pollution control board study, 2003.

[2] 'The Hindu' dated 25/09/03 and central pollution control board study, 2003.

[3] DGFT government of India 2001.

[4] Statistics of foreign trade of India march 2000.

[5] Environment protection agency U.K. 1998

[6] Uemichi Y., Kashiwaya Y., Tsukidte M , Ayame A , Kanoh H. (1983) Bull . Chem.Soc. Jpn., 56, 2768.

[7] Audisio G., Bertini F., Belteame P.L. , Carniti P., Makromol. (1992) Chem. Macromol. Symp. 57, 191.

[8] Ohkita H., Nishiyama R. , Tochihara T., Mizushima T. , Kakuta N. , Morioka Y. , Ueno A., Namiki Y.., Tanifuji S. , Katoh H., Sunazyka H., Nakayama R. , Kuroyanagi T. (1993) Ind. Eng. Chem.. Res., 32, 3112.

[9] Songip A.R., Masuda T., Kuwahara H., Hashimoto K. (1993) Appl. Catal. B: Environ., 2,153.

[10] Songip A.R., Masuda T., Kuwahara H., Hashimoto K. (1994) Energy Fuels, 8,131.

[11] Ng S.H., Seoud H., Stanciulescu M., Sugimoto Y. (1995) Energy Fuels, 9,735.

[12] Uddin M.A., Sakata Y., Koziumi K., Zaki M.N., Murata K. (1996) Polym. Recycle, 2,309.

[13] Uddin M.A., Sakata Y., Kozoumi K., Murata K. (1997) Polym. Degrad. Stab., 56,37.

[14] Abajo I., Lopez- Valerio D. , Fernandez I., Azkoiti M.J., Olazar M., Bilibao J. (1997) Ind. Engg. Chem. Res., 36,4523.

[15] Delapuente G., Arandres J.M., Sedran U.A. (1997) Ind. Engg. Chem. Res., 36,4530.

[16] Arandes J.M., Eeana J., Azokoiti M.J, Lopez -Velerio D., Bilbao J. (2004) Fuel Process. Technol. , 85,125.

[17] Arguado J., Soltelo J.L., Serrano D.P., Calles J.A., Escola J.M. (1997) Energy Fuels , 11,1225. 
Table I-

\begin{tabular}{|l|l|l|l|}
\hline $\begin{array}{l}\text { Polymer } \\
\text { catalyst } \\
\text { ratio }\end{array}$ & $\begin{array}{l}\text { Polymer } \\
\text { mass }(\mathrm{g})\end{array}$ & $\begin{array}{l}\text { Catalyst } \\
\text { mass }(\mathrm{g})\end{array}$ & $\begin{array}{l}\text { Total } \\
\text { mass }(\mathrm{g})\end{array}$ \\
\hline & & 1.5 & 3 \\
\hline $1: 01$ & 1.5 & 1.01 & 3.02 \\
\hline $2: 01$ & 2.01 & 0.51 & 2.56 \\
\hline $4: 01$ & 2.05 & 0.36 & 2.49 \\
\hline $6: 01$ & 2.13 & & \\
\hline Catalyst 2 & & 1.52 & 3.04 \\
\hline $1: 01$ & 1.52 & 1.02 & 3.06 \\
\hline $2: 01$ & 2.04 & 0.56 & 2.82 \\
\hline $4: 01$ & 2.26 & & \\
\hline
\end{tabular}

Table II-

\begin{tabular}{|l|l|l|l|l|}
\hline $\begin{array}{l}\text { Poly. } \\
\text { Cat. } \\
\text { Ratio }\end{array}$ & $\begin{array}{l}\text { Conversion } \\
(\%)\end{array}$ & $\begin{array}{l}\text { Yield to } \\
\text { liquid } \\
\text { product } \\
(\%)\end{array}$ & $\begin{array}{l}\text { Coke } \\
\text { yield (\%) }\end{array}$ & $\begin{array}{l}\text { Coke } \\
\text { concentration }\end{array}$ \\
\hline Catalyst1 & & & & \\
\hline $1: 01$ & 98 & 66 & 2 & 2 \\
\hline $2: 01$ & 99 & 76 & 1 & 2 \\
\hline $4: 01$ & 99 & 89 & 1 & 4 \\
\hline $6: 01$ & 99 & 73 & 1 & 6 \\
\hline Catalyst & & & & \\
\hline 2 & 94 & 41 & 6 & 6 \\
\hline $1: 01$ & 94 & 66 & 5 & 10 \\
\hline $2: 01$ & 95 & 78 & 7 & 28 \\
\hline $4: 01$ & 93 & & & \\
\hline
\end{tabular}

Table III- Typical analysis of gaseous product from process is as follows

\begin{tabular}{|l|l|l|}
\hline S.NO. & Component & Quantity in wt\% \\
\hline 1 & methane & 6.6 \\
\hline 2 & $\begin{array}{l}\text { Ethane } \\
\text { Ethylene }\end{array}$ & 10.6 \\
\hline 3 & Propane & 7.4 \\
\hline 4 & Propylene & 29.1 \\
\hline 5 & Iso-butane & 1.9 \\
\hline 6 & n-butane & 0.9 \\
\hline 7 & C4 (unsaturated) & 25.6 \\
\hline 8 & Iso-C5, n-C5 & 0.1 \\
\hline 9 & C5 + Higher & 15.3 \\
\hline 10 & Hydrogen & 2.5 \\
\hline 11 & CO/CO2 & $<400 \mathrm{ppm}$ \\
\hline
\end{tabular}


Table IV Typical analysis of liquid hydrocarbons obtained:

\begin{tabular}{|l|l|l|}
\hline S.NO. & Carbon No. & $\begin{array}{l}\text { Quantity in } \\
\text { wt\% }\end{array}$ \\
\hline 1 & Up to C10 & 61 \\
\hline 2 & C10 to C13 & 2.4 \\
\hline 3 & C13 to C16 & 8.5 \\
\hline 4 & C16 to C20 & 4.1 \\
\hline 5 & C20 to C23 & 7.6 \\
\hline 6 & C23 to C30 & 16.4 \\
\hline
\end{tabular}

Table V- Properties of crude oil obtained

(When zeolite type 5A is mixed with catalyst \& kept in receiver and product is filtered.)

\begin{tabular}{|l|l|l|}
\hline Properties & $\begin{array}{l}\text { Regular } \\
\text { gasoline }\end{array}$ & $\begin{array}{l}\text { Fuel } \\
\text { extracted } \\
\text { from } \\
\text { waste } \\
\text { plastic }\end{array}$ \\
\hline Color, Visual & Orange & $\begin{array}{l}\text { Pale } \\
\text { Yellow }\end{array}$ \\
\hline Specific Gravity at 280 C & 0.7423 & 0.7254 \\
\hline Specific gravity at 150 C & 0.7528 & 0.7365 \\
\hline Gross Calorific Value & 11210 & 11262 \\
\hline Net Calorific Value & 10460 & 10498 \\
\hline API Gravity & 56.46 & 60.65 \\
\hline Sulphur Content & 0.1 & 0.002 \\
\hline Flash Point (Abel) 0 C & 23 & 22 \\
\hline Pour Point 0 C & $<-20 ~ 0 ~ C$ & $<-200 \mathrm{C}$ \\
\hline Cloud Point 0 C & $<-20$ C & $<-200 \mathrm{C}$ \\
\hline Existent Gum, gm/m3 & 40 & 36 \\
\hline Reactivity with SS & $\mathrm{Nil}$ & Nil \\
\hline Reactivity with MS & $\mathrm{Nil}$ & $\mathrm{Nil}$ \\
\hline Reactivity with Cl & $\mathrm{Nil}$ & $\mathrm{Nil}$ \\
\hline Reactivity with Al & $\mathrm{Nil}$ & $\mathrm{Nil}$ \\
\hline Reactivity with Cu & $\mathrm{Nil}$ & $\mathrm{Nil}$ \\
\hline
\end{tabular}

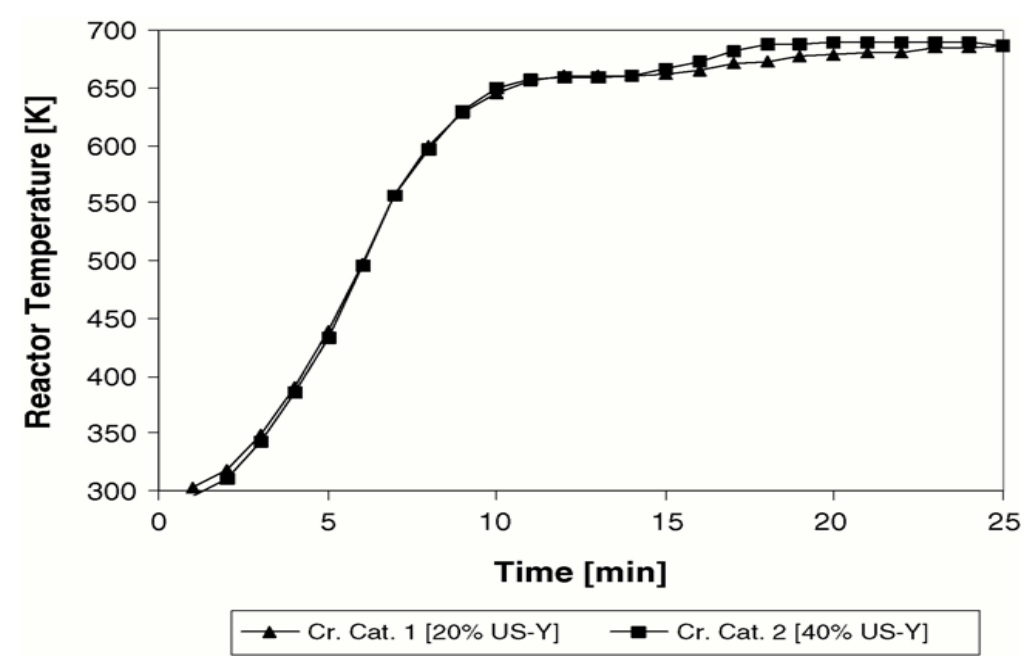

Fig. I- graph between temperature achieved and time of reaction. 


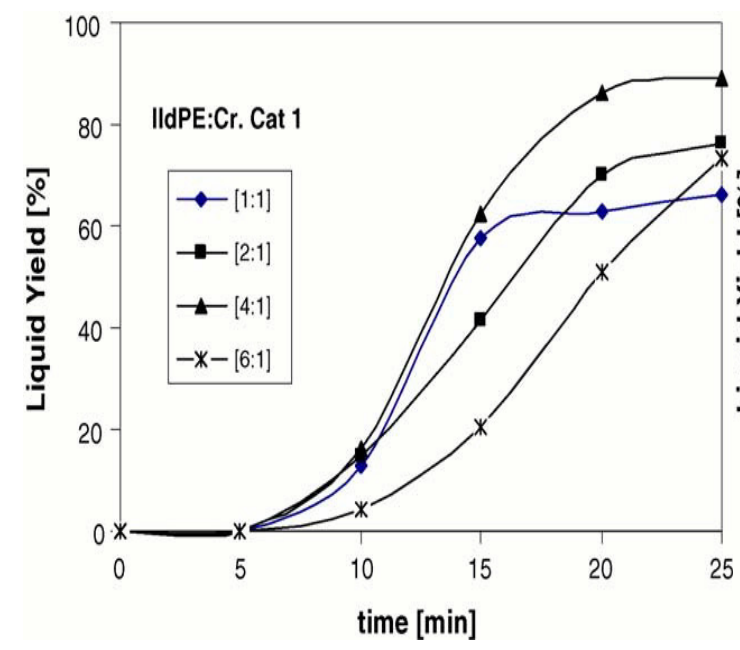

Fig. II

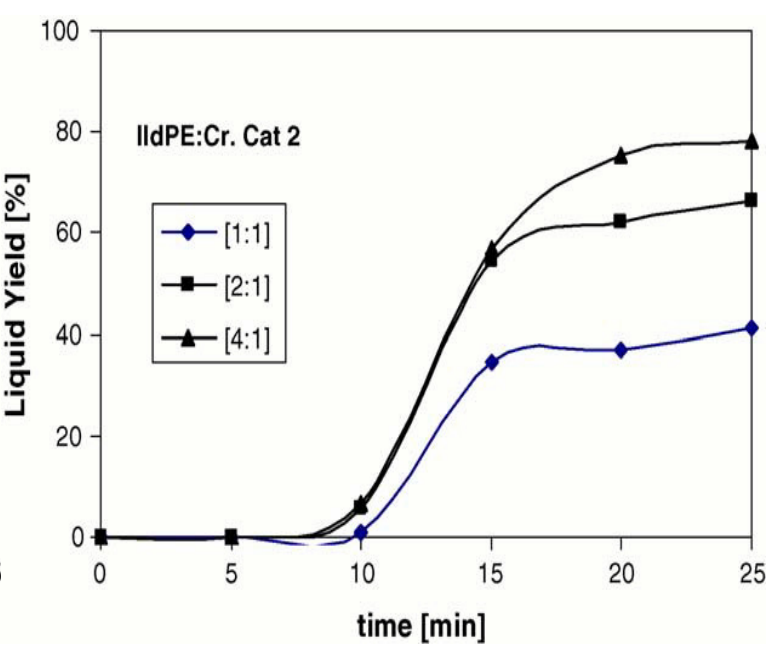

Fig.III

Graph between liquid yield and time taken for various polymer to catalyst ratio.
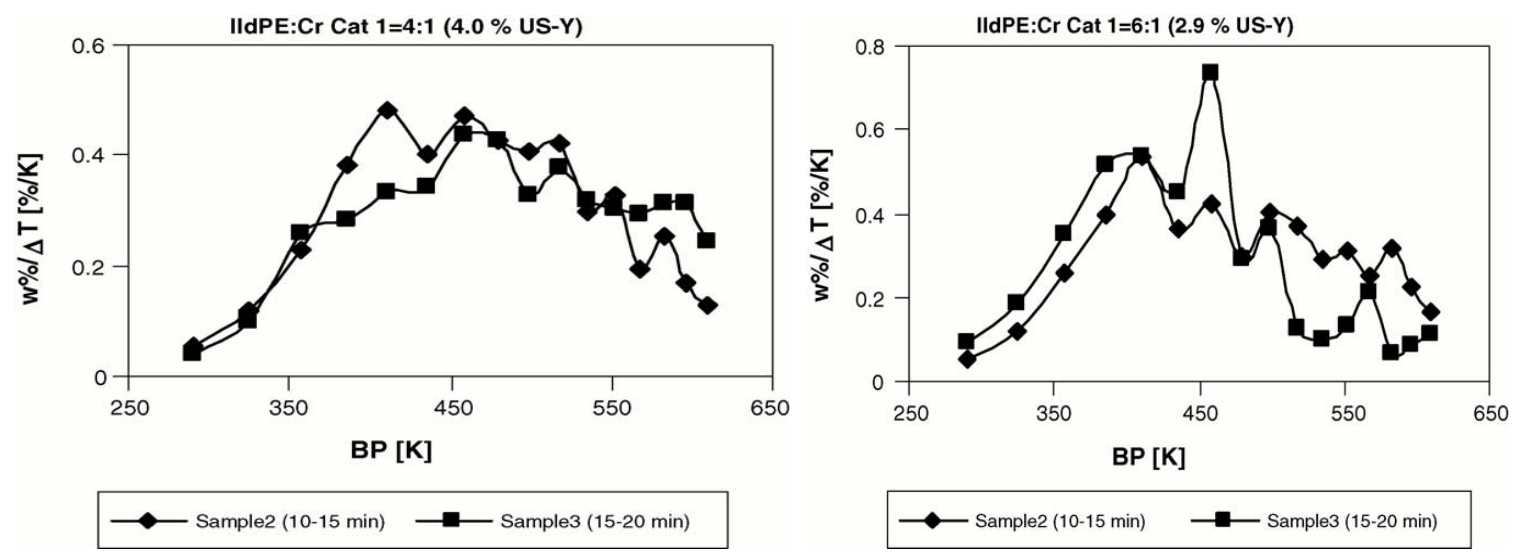

Fig. IV

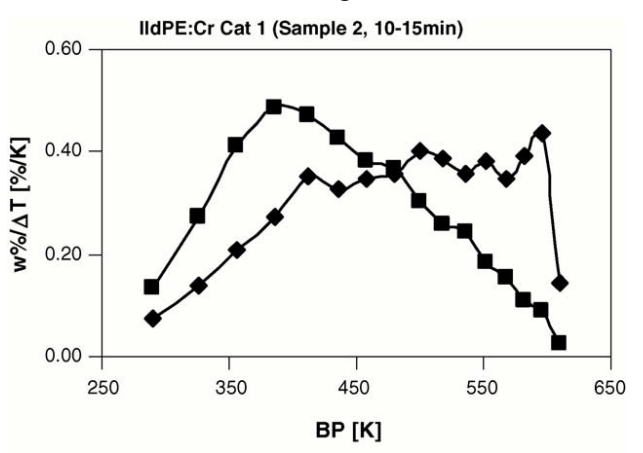

$\longrightarrow \mathrm{IdPE:Cr}$ Cat $1=2: 1 \longrightarrow \mathrm{IdPE}: \mathrm{Cr}$ Cat $1=1: 1$

Fig.VI

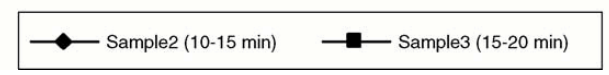

Fig.V

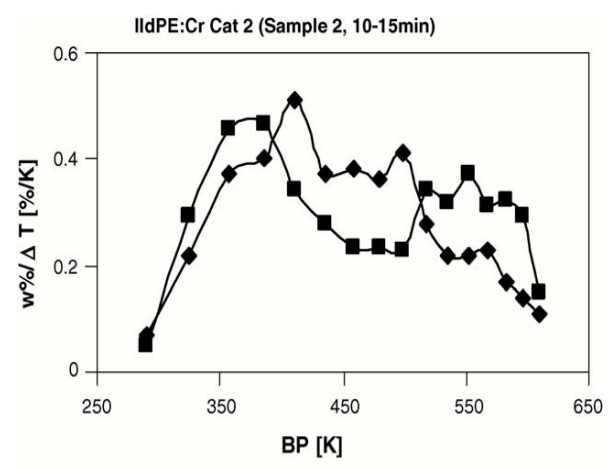

$\longrightarrow$ IIPE:Cr Cat $2=2: 1 \quad$ IIdPE:Cr Cat 2 $=1: 1$

Fig. VII 